\title{
- Aguapé (Eichbornia crassipes): Uma alternativa alimentar para bovinos de pequenas propriedades no perímetro da represa Billings - Estado de São Paulo, Brasil
}

- Pond lily (Eichhornia crassipes): a food alternative for cattle in small farms close to the Billings dam - State of São Paulo, Brazil
*Praça Aquiles de Almeida $n^{\circ} 90$ CEP 04149-070 - São Paulo - SP e-mail: mauricio@uniabc.br

\footnotetext{
* Maurício Garcia ${ }^{1}$-CRMV-SP n 3980

Aparecido Klai ${ }^{2}$

Cristiane Marcusso ${ }^{2}$

IviCaroline CostaAndretta ${ }^{2}$

${ }^{1}$ Docente do Curso de Medicina Veterinária da Universidade do Grande ABC.

2 Alunos do Curso de Medicina Veterinária da Universidade do Grande ABC.
}

\section{RESUMO}

A Eichhornia crassipes (Aguapé) é uma planta aquática distribuída por toda a extensão do território brasileiro. Suas raízes possuem a capacidade de filtrar poluentes da água onde se desenvolve. Seus bulbos e folhas prestam-se à alimentação animal. Por sua propagação agressiva tem-se a necessidade de controlar a sua expansão de forma a proteger os recursos hídricos. A represa Billings, no Estado de São Paulo, apresenta áreas onde o aguapé se desenvolve naturalmente. Pequenos produtores de leite na proximidade não se utilizam deste recurso natural para a alimentação dos animais; diante disso, o presente trabalho objetiva apresentar o aguapé como alternativa para alimentação de bovinos destas regiões, sem que haja implemento na degradação ambiental e, simultaneamente, controlando-se a sua demasiada capacidade reprodutiva.

Palavras-chave: aguapé, bovinos, alimentação.

\section{Introdução}

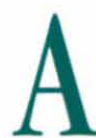

Eichhornia crassipes, também conhecida por aguapé, baronesa, jacinto d'água ou rainha-dos-lagos, dentre tantos outros nomes, é uma planta aquática originária da América Central (SILVA et al., 1978; KWAI et al., 1986).
Aguapé é uma palavra que tem origem no idioma dos índios tupis (significa redondo e chato) e transformou-se num dos nomes populares atribuídos a uma vasta quantidade de plantas aquáticas e flutuantes de diversas famílias que possuem folhas arredondadas e chatas. A Eichhornia crassipes (Figura 1) é uma destas espécies e é considerada, dentre todas, a de maior expansão vegetativa (CORRÊA, 1984). 
GARCIA, M.; KLAI, A.; MARCUSSO, C.; ANDRETTA, I. C. C. Aguapé (Eichhornia crassipes): Uma alternativa alimentar para bovinos de pequenas propriedades no perímetro da represa Billings - Estado de São Paulo, Brasil. / Pond lily (Eichhornia crassipes): a food alternative for cattle in small farms close to the Billings dam - State of São Paulo, Brazil. Rev. educ. contin. CRMV-SP / Continuous Education Journal CRMV-SP, São Paulo, volume 3, fascículo 3, p. 37 - 43, 2000.

Originária da América Central, essa planta, que se desenvolve bem em água doce de rios, lagos ou represas, expandiu-se para zonas tropicais e subtropicais, chegando a produzir 212 toneladas de matéria seca por hectare/ ano em águas poluídas (SILVA et al., 1978; KWAI et al., 1986). Pode ser confundida com a Eichhornia azurea, planta da mesma família e com semelhante potencial de aproveitamento que é encontrada desde o México até a Argentina, porém não tão produtiva quanto a $E$. crassipes (VEITENHEIMER-MENDES, 1993).

Em reservatórios de geração de energia elétrica essa demasiada produtividade necessita de controle. É comum o uso de herbicidas, o que provoca a redução dos teores de oxigênio dissolvido na água durante a decomposição da planta, alterando o fitoplancton e o zoo-

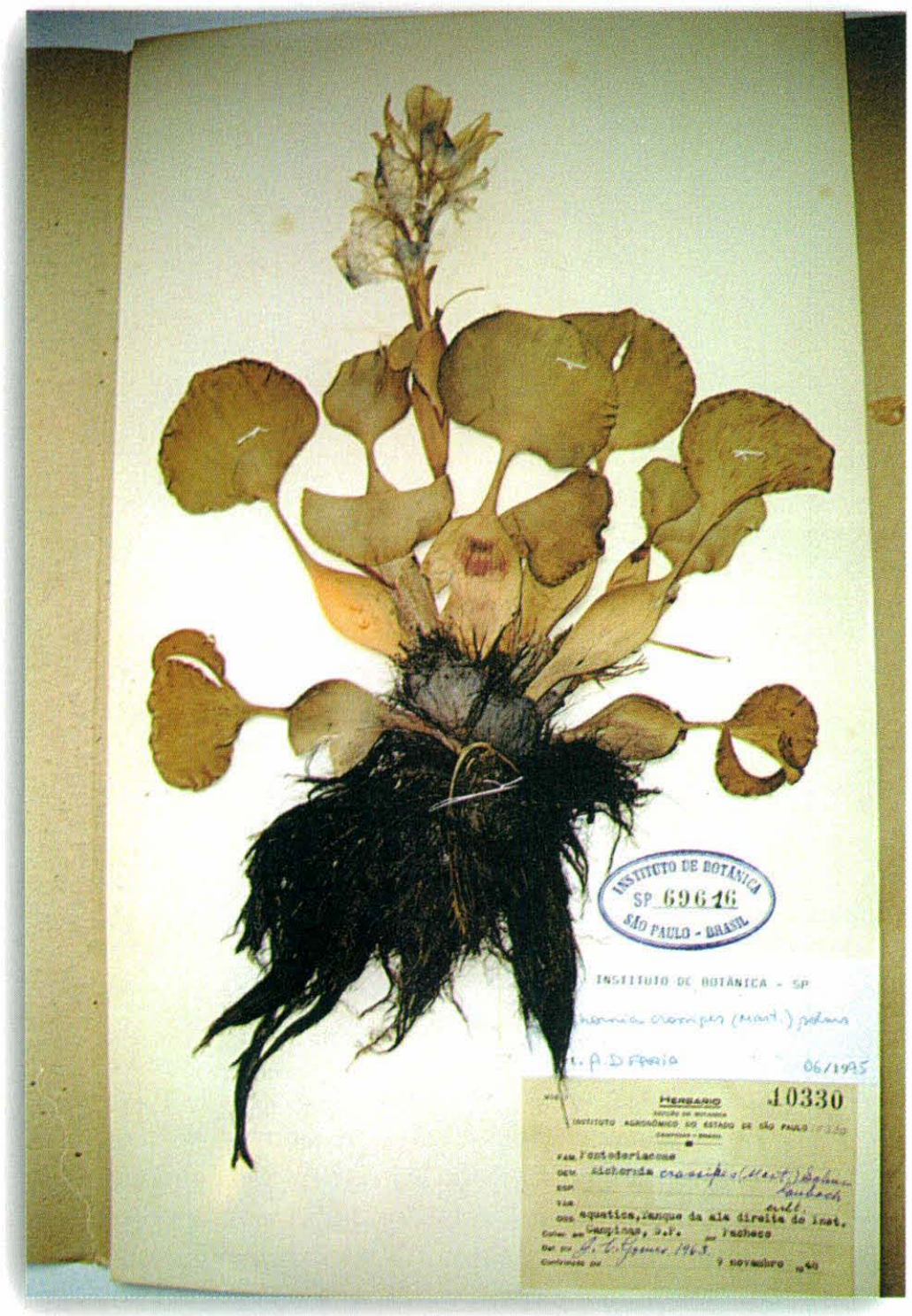

Figura 1. Reprodução fotográfica da Eichhornia crassipes - planta do acervo do herbário do Instituto de Botânica de São Paulo plancton, desencadeando conseqüências negativas à cadeia ecológica e contaminando o ambiente. Uma forma de controle não poluente, embora pouco produtiva, é a retirada mecânica da planta do meio aquático (STRANO, 1987; GELMINI, 1996).

Os corpos d'água cuja superfície se revestem de aguapé apresentam menores índices de variação térmica, porém, em contrapartida, a perda por evapotranspiração aumenta entre 50 e $300 \%$, quando comparada com corpos d'água livres desta cobertura vegetal, condição que inspira preocupação principalmente nos meses de estiagem e quando se tratam de reservatórios de água para consumo (STRANO, 1987).

Sua agressiva expansão vegetativa e significativa produção de matéria seca, aliadas ao fato de ser palatável a algumas espécies animais de interesse econômico, inclusive bovinos, torna essa planta uma espécie passível de aproveitamento econômico nas regiões aonde se desenvolve com sua agressividade natural e se faz necessário um controle de sua expansão.

\section{Aspectos botânicos}

A Eichhornia crassipes possui um caule curto e um tufo de raízes finas e pilosas que podem atingir até $60 \mathrm{~cm}$ de comprimento (Figuras 1 e 2). Suas raízes são responsáveis pela filtração de poluentes das águas e local de desova, abrigo e alimento para algumas espécies de peixes (RIBEIRO et al., 1986; LORENZI, 1991), podendo abrigar também o caramujo hospedeiro intermediário das cercárias do Schistosoma, transmissor da esquistossomose (URQUHART et al., 1998). Sua inflorescência apresenta-se em espigas de 8 a 15 cm e de 8 a 38 flores por inflorescência (LORENZI, 1991). As flores são arroxeadas com desenhos mais escuros e uma mácula amarela no lábio inferior. Floresce de janeiro a fevereiro (HOEHNE, 1979), sendo considerada bastante decorativa (GEMTCHUJNICOV, 1976). Suas folhas são arredondadas, chatas e dispostas em rosetas com longos pecíolos esponjosos e inflados que permitem a flutuação (HOEHNE, 1979; LORENZI, 1991).

Considerada como a mais séria planta daninha aquática do país e com potencial de aumento de área de $15 \%$ ao dia, sendo capaz de dobrála em apenas seis ou sete dias, pode produzir 480 toneladas/ha/ano, de massa verde (LORENZI, 1991). SILVA et al. (1978) relatam uma expres- 


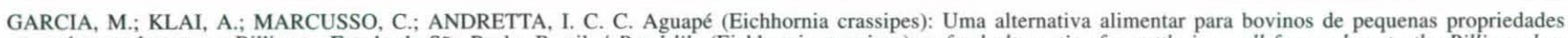

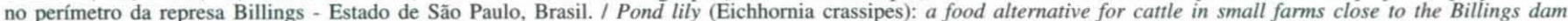
- State of São Paulo, Brazil. Rev. educ. contin. CRMV-SP / Continuous Education Journal CRMV-SP, São Paulo, volume 3, fascículo 3, p. 37 - 43, 2000.

siva produção de 212 toneladas de matéria seca por hectare/ano quando em águas poluídas mas ricas em nutrientes.

A E. crassipes multiplica-se a partir de estolhos ou sementes, que podem ficar dormentes na água por um período de até quinze anos e agrupam-se em colônias, formando ilhas flutuantes. Eventualmente pequenas porções dos aglomerados maiores podem desprender-se e deslocar-se com o vento, ou com o movimento das águas, indo formar nova colônia noutro local do lago, rio ou represa (HOEHNE, 1979; CORRÊA, 1984). São também potencialmente danosas aos sistemas de geração de energia elétrica das barragens.

Alcançando a América do Sul, essa planta espalhou-se por mais de 50 países do mundo (KWAI, 1986). Foi levada para o continente asiático como planta ornamental, chegou a ser considerada uma praga na Flórida (EUA), Austrália, Índia, Birmânia, Congo, Brasil e outros países, em função dos danos causados aos sistemas hídricos, absorvendo consideráveis somas no seu controle (CORRÊA, 1984; KWAI et al., 1986).

Pode infestar canais de irrigação e rios, dificultando o fluxo, provocando estagnação das águas e formação de brejos (GEMTCHUJNICOV, 1976).

A sua abundância no território nacional, aliada às suas características de fácil propagação, capacidade filtrante das raízes, possibilidade de utilização para fabricação de rações, compostos orgânicos e biogás, levou alguns pesquisadores brasileiros a realizar experimentos,

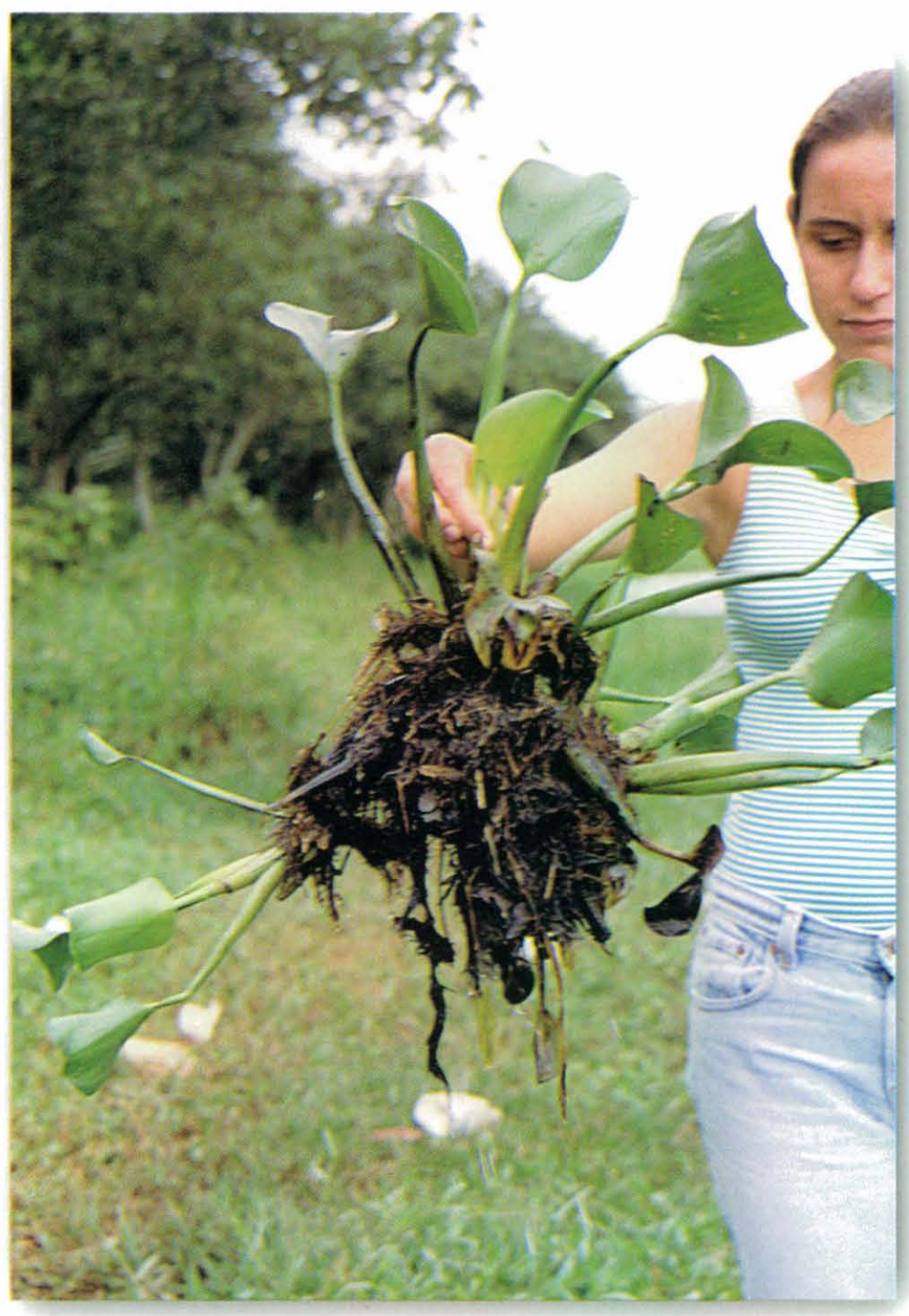

Figura 2. Eichhornia crassipes, recolhida junto a represa Billings em fevereiro de 2000.

objetivando o tratamento do esgoto doméstico pelo aguapé e a exploração de todo o potencial da planta, inclusive na alimentação humana (SILVA et al., 1978; CARVALHO, 1984; RIBEIRO et al., 1986; KWAI et al., 1986).

\section{Uso comercial}

STRANO (1987) refere que a partir do suco extraído da massa seca do aguapé, e posterior eliminação da umidade, é possível obter-se um farelo insípido constituído em cerca de $5 \%$ por proteína, com potencial de utilização na alimentação humana ou animal.

Segundo Corrêa (1984), a Eichhornia crassipes é utilizada na engorda de suínos na Birmânia e provoca uma alteração para melhor no sabor da carne.
KWAI et al. (1986) relatam a utilização da Eichhornia crassipes desidratada na alimentação de coelhos de corte, frangos de corte e galinhas poedeiras apontando a planta como fonte segura de xantofilas, o que melhora a coloração da gema dos ovos.

Rebanhos bovinos de criação extensiva na ilha de Marajó e no Mato Grosso do Sul consomem a planta como forrageira, colhendo-a diretamente em áreas alagadas, dentro do perímetro de suas áreas de pastagem (CORRÊA, 1984).

LORENZI (1991) destaca uma produção de 480 toneladas/ha/ano de massa verde. SILVA et al. (1978) relatam que sua produção é de 212 toneladas de matéria seca por ha/ano quando em águas poluídas mas ricas em nutrientes. Produção bastante superior à das forrageiras utilizadas na pecuária. 
GARCIA, M.; KLAI, A.; MARCUSSO, C.; ANDRETTA, I. C. C. Aguapé (Eichhornia crassipes): Uma alternativa alimentar para bovinos de pequenas propriedades no perímetro da represa Billings - Estado de São Paulo, Brasil. I Pond lily (Eichhornia crassipes): a food alternative for cattle in small farms close to the Billings dam - State of São Paulo, Brazil. Rev. educ. contin. CRMV-SP / Continuous Education Journal CRMV-SP, São Paulo, volume 3, fascículo 3, p. 37 - 43, 2000.

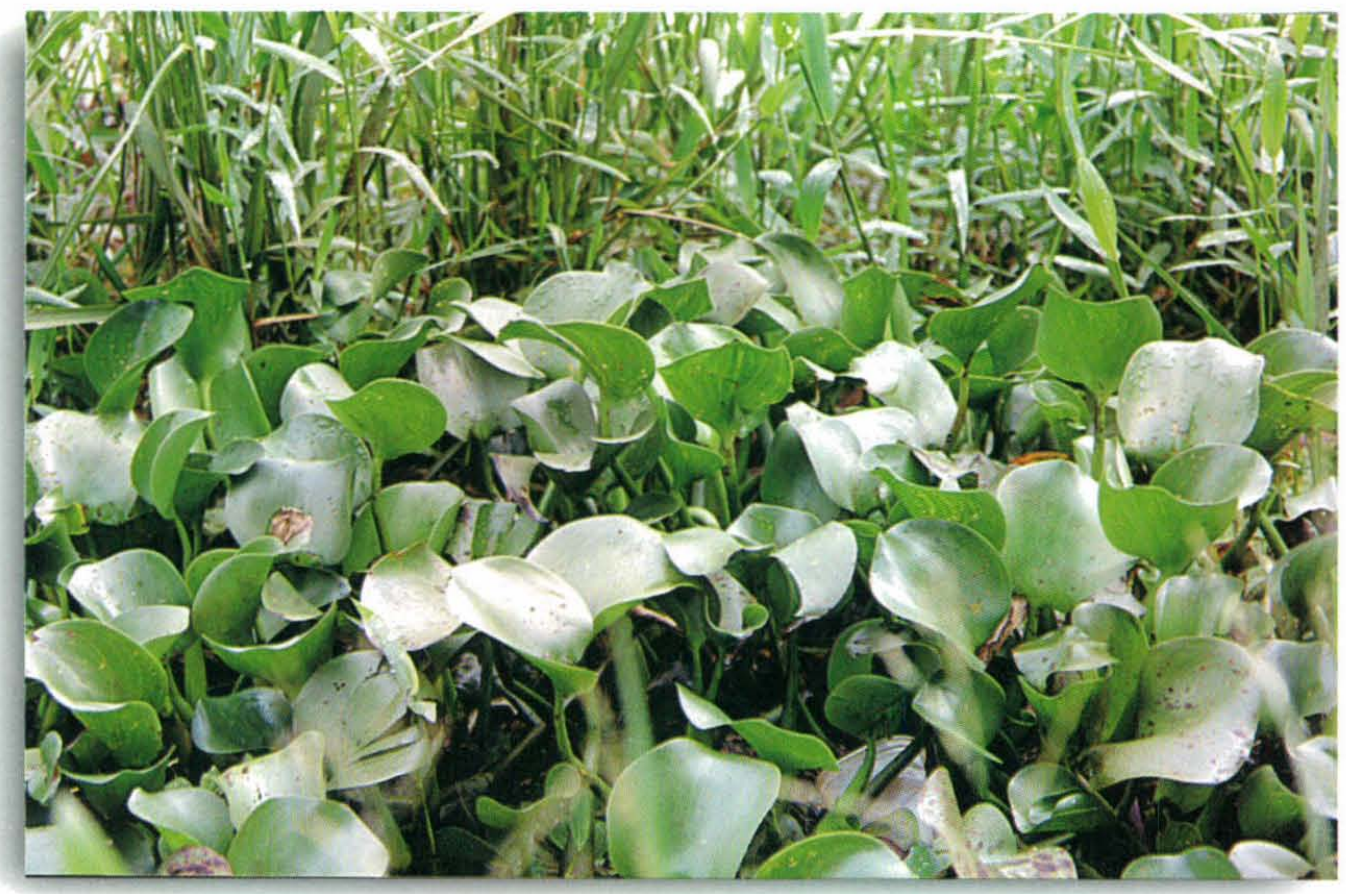

Figura 3. Eichhornia crassipes, represa Billings, Ribeirão Pires (SP), fevereiro de 2000.

Um híbrido produzido a partir do cruzamento do capim elefante (Pennissetum purpureum) com o milheto (Pennisetum glaucum), pode produzir até 50 toneladas/ha/ano de matéria seca com teores de proteína bruta de 8 a $18 \%$ (PRUDENET, 2000).

Cerca de $85 \%$ da massa do aguapé é constituída de água, sendo seu teor de proteína muito variável em função das condições da água em que se desenvolve. SILVA et al. (1978) relatam valores de 4,9 a $6,4 \%$ de proteína bruta, de 4,3 a $5,2 \%$ de fibra e de 4,6 a $5,7 \%$ de cinzas (Ta-

A Brachiária decumbens pode produzir 45 toneladas/ha/ano de massa verde (NATERRA, 2000). Em XAVIER et al. (1998) a B. decumbens constitui $30 \%$ das áreas de pastagens cultivadas no país e produz 0,87 e 2,33 toneladas/ha/mês de matéria seca nos períodos da seca e das águas respectivamente. Em CAPRIO et al. (1999) a B. decumbens é considerada, dentro do gênero, a espécie de maior potencial produtivo.

$\mathrm{O}$ girassol cultivado para silagem atinge uma produção de 70 toneladas/ha/ano, sendo que $25,42 \%$ dessa massa resulta em matéria seca (KOGA, 1999). bela 1), numa produção de 4 toneladas de biomassa molhada/ha/dia, além de alta proporção em peso seco de carbono, hidrogênio, nitrogênio, potássio, sódio, cálcio, fósforo, enxofre, magnésio, ferro, zinco e manganês.

CORRÊA (1984) aponta que as cinzas representam apenas $1 \%$ do peso da planta verde e que, dentre seus constituintes, estão $28,7 \%$ de potássio, $21 \%$ de cloro, $12 \%$ de cal, $7,0 \%$ de anidrido fosfórico, $1,8 \%$ de soda e $0,59 \%$ de magnésio. A planta verde contém também 1,28\% de azoto. KWAI et al. (1986),

Tabela 1. Composição bromatológica do aguapé (E. crassipes) a partir do farelo desidratado.

\begin{tabular}{|l|c|c|c|c|}
\hline \multicolumn{1}{|c|}{$\begin{array}{c}\text { Autor } \\
\text { Ano }\end{array}$} & $\begin{array}{c}\text { KWAl et al. } \\
1986\end{array}$ & $\begin{array}{c}\text { GRANDI } \\
1982\left(^{*}\right)\end{array}$ & $\begin{array}{c}\text { SILVA et al. } \\
1978\end{array}$ & $\begin{array}{c}\text { TEJADA e } \\
\text { CERVANTES } \\
\text { 1974 (*) }\end{array}$ \\
\hline Matéria seca (\%) & 87,94 & 84,46 & - & - \\
Proteína bruta (\%) & 7,61 & 10,77 & 4,9 a 6,4 & - \\
Matéria mineral (\%) & 21,60 & 14,51 & - & - \\
Estrato etéreo (\%) & 2,01 & - & - & - \\
Fibra bruta (\%) & 17,32 & 17,80 & 4,3 a 5,2 & - \\
Estrato não nitrogenado (\%) & 39,40 & 51,13 & - & - \\
Cálcio (\%) & 1,08 & - & - & - \\
Fósforo (\%) & 0,12 & - & 4,6 a 5,7 & - \\
Cinzas (\%) & - & - & - \\
\hline
\end{tabular}

(*) Apud KWAl et al. (1986) 


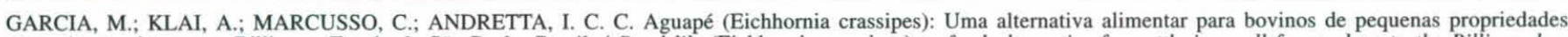

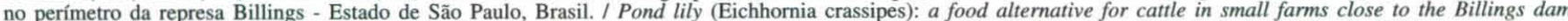
- State of São Paulo, Brazil. Rev. educ. contin. CRMV-SP / Continuous Education Journal CRMV-SP, São Paulo, volume 3, fascículo 3, p. 37 - 43, 2000.

que destacam o alto teor de caroteno e $7,61 \%$ de proteína bruta.

TEJADA e CERVANTES (1974) apud KWAI et al. (1986) analisando 37 amostras de aguapé encontraram valores de proteína bruta variando de 2,3 a $28,4 \%$ sobre a matéria seca (Tabela 1). PUPO (2000) constatou que os percentuais dos constituintes da planta em análises bromatológicas variavam conforme as características edafoclimáticas da região de cultivo, tipo de adubação, idade da planta, época do ano e manejo empregado. PALOMBO et al. (1991) consideram que a composição do aguapé está relacionada principalmente aos teores de matéria orgânica da água em que se desenvolve, temperatura ambiente, idade e época de colheita.

A título de comparação, forrageiras como o capim elefante apresentam $15,9 \%$ de proteína bruta e o capim gordura, com 155 dias, 2,4\%. Sempre se comparando os valores de proteína bruta com de matéria seca (FREITAS, 1978), enquanto a alfafa, no Brasil, tem sua produção variando de 6 a 20 toneladas/ha/ano de matéria seca (dependendo de cada condição de plantio), com valores médios de $25 \%$ de proteína bruta (CAPRIO et al.,1999).

\section{Potencial de uso na represa Billings}

A represa Billings, no Estado de São Paulo, ocupa uma área aproximada de 130 quilômetros quadrados, formando um imenso reservatório de água doce, que ocupa áreas das cidades de Santo André, São Bernardo do Campo, Diadema, Ribeirão Pires e da própria Capital paulista, onde a Eichhornia crassipes (Figura 3) pode ser encontrada em alguns de seus trechos (PALOMBO et al., 1991).

Em muitas destas áreas, no perímetro da represa Billings, reguladas pela Lei de Proteção dos Mananciais, especificamente na região que corresponde ao $\mathrm{ABC}$ paulista, existem pequenas propriedades de atividades agrícolas e de pecuária. Em 19 propriedades visitadas em $1999,79 \%$ possuíam área inferior a 5 hectares, com um rebanho médio de 12 cabeças por propriedade e uma produção leiteira de 3,2 litros/cabeça/dia. Com escassas áreas de pastagens, os animais destas propriedades recebiam uma suplementação alimentar de capim elefante ou, de acordo com o recurso de cada produtor, alternativas como resíduos de indústrias alimentícias. Não há relato da utilização do aguapé na alimentação de bovinos nestas propriedades (KLAI et al., 1999).

De acordo com o NATIONAL RESEARCH COUNCIL (1989), animais com $400 \mathrm{Kg}$ de peso vivo e
Quadro 1. Utilização da Eichhornia crassipes na alimentação de bovinos

Utilizar apenas a parte aérea da planta

Desidratar na sombra

Triturar ou não (dependendo do recurso do produtor)

Servir no cocho na proporção de $2 \%$ do peso vivo de cada animal

produção leiteira de $10 \mathrm{Kg} /$ dia com $4 \%$ de gordura devem consumir $2,5 \%$ de seu peso em matéria seca; enquanto que com 500,600 e $700 \mathrm{Kg}$ de peso vivo e mesma produção leiteira, os valores são de $2,3 \%, 2,2 \%$ e $2,1 \%$ respectivamente. CAMPOS e LIZIERE (1997) recomendam como regra geral o consumo de $2 \%$ do peso vivo em matéria seca. Animais com $600 \mathrm{Kg}$ de peso vivo e produção leiteira de $10 \mathrm{Kg} /$ dia (mais de 3 vezes superior a média da região), necessitam consumir 13,2 Kg/MS/dia. O aguapé, com uma produção de 212 toneladas/ha/ano de matéria seca (SILVA et al., 1978), pode contribuir na alimentação de 44 animais/ha/ ano. Em termos de proteína bruta, para o exemplo em questão, a ingestão/dia recomendada pelo NATIONAL RESEARCH COUNCIL (1989) é de $14 \%$.

Segundo LUCCI (1997), o consumo de matéria seca por bovinos depende de fatores como o peso, o nível de produção, condições ambientais, fatores de manejo, condição física, tipo e qualidade dos alimentos, notadamente das forragens volumosas.

O consumo de matéria seca com bons percentuais de proteína bruta concorre para um bom crescimento e resistência às infecções pelo organismo animal (LUCCI, 1989).

A presença de cálcio e fósforo no aguapé (Tabela 1) é um aspecto positivo, pois, ambos participam da composição dos ossos e dos dentes. Segundo MAYNARD e LOOSLI (1974) o cálcio está envolvido no processo de contração muscular, e $15 \%$ do fósforo do organismo é encontrado em tecidos moles e fluidos orgânicos. A carência de fósforo causa a perda ou o apetite depravado e a deficiência do cálcio implica na mobilização do cálcio ósseo, resultando em menor crescimento e diminuição da resistência óssea.

O caroteno relatado por KWAI et al. (1986) é também relevante pois o organismo animal o converte em vitamina A. Uma carência de vitamina A implica em crescimento retardado e queda das taxas reprodutivas (MAYNARD e LOOSLI, 1974). Ocorre uma degeneração das mucosas tornando o animal suscetível a infecções (LUCCI, 1997). 


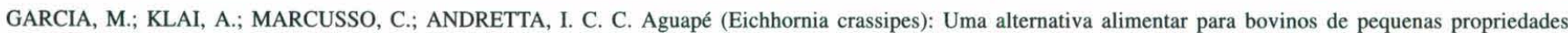

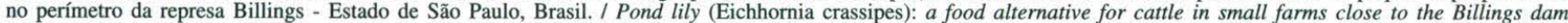
- State of São Paulo, Brazil. Rev. educ. contin. CRMV-SP / Continuous Education Journal CRMV-SP, São Paulo, volume 3, fascículo 3, p. 37 - 43, 2000.

Segundo FREITAS (1978), a alimentação é responsável por até $49 \%$ dos custos da produção de leite e, por ser o componente de custo mais elevado na produção de leite ou de carne, uma alimentação menos onerosa propicia menor custo de produção, melhor produtividade, competitividade e, consequentemente, maior margem de lucro.

Os pequenos produtores do perímetro da represa Billings, face a sua escassez de pastagens (KLAI et al., 1999) tem como alternativa a utilização do aguapé, mais especificamente suas partes aéreas (Quadro 1), desprezando-se as raízes onde se concentram os poluentes filtrados (STRANO, 1987). A planta desidratada pode ser servida no cocho, triturada ou não (LUTZEMBERGUER,
1992), na proporção de $2 \%$ do peso vivo de cada animal (CAMPOS e LIZIERE, 1997).

Essa alternativa alimentar concorre simultaneamente para um controle da propagação da planta, redução dos recursos públicos empenhados neste controle e menor impacto ambiental, tanto quando há a necessidade de um controle químico, como quando o pequeno produtor substitui ilegalmente parte da reserva natural por pastagem ou por áreas de cultura.

Há que se destacar que a retirada da planta de seu ambiente deve obedecer critérios determinados pelos setores públicos responsáveis pelas áreas de mananciais, visto que se presta a abrigo e alimento de algumas espécies de peixes.

\section{SUMMARY}

Pond lilies (Eichhornia crassipes) are aquatic plants widely distributed all over Brazil. Their roots have the capacity of filtering water pollutants present where they develop, and bulbs and leaves are used for feeding cattle. It is necessary to protect water resources against their expansion. In the state of São Paulo, the Billings dam has areas where the pond lilies occur and, as the small dairy farms in the neighborhood do not use them, the objective of this study was to introduce the pond lily as an alternative to feed their animals. In this way, there will not be any environment degradation and it will be possible to control the pond lilies excessive propagation.

Key words: pond lily, cattle, feeding.

\section{REFERÊNCIAS BIBLIOGRÁFICAS}

1 - CAMPOS, O. F.; LIZIERE, R. S. Gado de leite - o produtor pergunta a Embrapa responde. Coronel Pacheco: Embrapa/CNPGL, 1997. 213p.

2 - CAPRIO, A.; CARRER, C. C.; CARRER. C. R. O.; et al. Apostila do curso de criação de avestruzes. Pirassununga: Brasil Ostrich, 1999. 72p.

3 - CARVALHO, B. C. Aguapé, solução natural para poluição das águas. São Paulo: CETESB, 1984. 2p.

4 - CORRÊA, M. P. Dicionário das plantas úteis do Brasil e das exóticas cultivadas. Rio de Janeiro: Imprensa Nacional, 1984. v. 1,747 p.

5 - FREITAS, L. M. M. Exploração leiteira: melhor utilização de forrageiras na região geo-econômica de São Paulo. São Paulo: Editora dos Criadores, 1978. 170p.

6 - GELMini, G. A. Controle químico do aguapé (Eichhornia crassipes) e da alface d'água (Pistia stratio- tes). Piracicaba, SP, 1996. Dissertação (Mestrado). Escola Superior de Agricultura Luiz de Queiroz. Universidade de São Paulo.

7 - GEMTCHUJNICOV, I. D. Manual de taxonomia vegetal; plantas de interesse econômico, agrícolas, ornamentais e medicinais. São Paulo: Editora Agrônoma Ceres, 1976. 370p.

8 - HOEHNE, F. C. Plantas aguáticas. São Paulo: Instituto de Botânica, 1979. 168p.

9 - KLAI, A.; GARCIA, J. M.; PUGLIESE, C.; SALGADO, J.; ANDREATTA, I. C. C.; ROSSI, V.; CUAMI, C.; GARCIA, M. Caracterização do perfil leiteiro na região do $\mathrm{ABC}$ paulista. In: CONGRESSO BRASILEIRO DE MEDICINA VETERINÁRIA, 26., Campo Grande, 1999. Anais. (em CD Rom).

10 - KOGA, C. Silagem de girassol, opção de dieta econômica. Balde Branco, São Paulo, n. 418, p.20-5, 1999. 


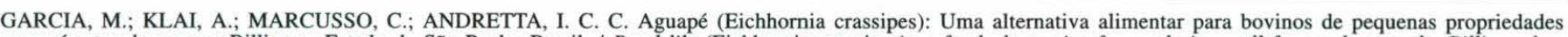

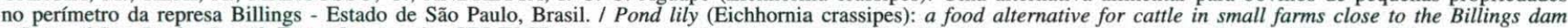
- State of São Paulo, Brazil. Rev. educ. contin. CRMV-SP / Continuous Education Journal CRMV-SP, São Paulo, volume 3, fascículo 3, p. 37 - 43, 2000.

11 - KWAI, H.; ARIKI, J.; MILEO, H. Substituição do farelo de trigo por aguapé (Eichhornia crassipes) desidratado em rações de poedeiras comerciais. São Paulo: CETESB, 1986. 35p.

12 - LORENZI, H. Plantas daninhas do Brasil: terrestre, aquáticas, parasitas, tóxicas e medicinais. 2 ed. Nova Odessa: Editora Plantarum, 1991. 440p.

13 - LUCCI, C. S. Bovinos leiteiros, nutrição, manejo, doenças. São Paulo: Manole, 1997. 169p.

14 - LUCCI, C. S. Nutrição e manejo de bovinos leiteiros. São Paulo: Nobel/Edusp, 1989. 371p.

15 - LUTZEMBERGUER, J. Ecologia: do jardim ao poder. Porto Alegre: L \& PM, 1992. 188p.

16 - MAYNARD, L. A.; LOOSLI, J. K. Nutrição animal. Rio de Janeiro: Freitas, 1974. 550p.

17 - NATERRA. Brachiária humidícola. (On line, 05/03/2000, http://www.naterra.com.br/graminea/brahumi.htm).

18 - NATIONAL RESEARCH COUNCIL. Nutrients requeriments of dairy cattle. Washington, D.C.: National Academy of Science, 1989. 159p.

19 - PALOMBO, C. R.; LEMOS, M. M. G.; PALOMBO, S. R. K. Avaliação da propagação vegetativa e germinativa e con- trole integrado de Eichhornia crassipes (aguapé) e Pistia stratiotes (alface d'água) em condições de Represa Billings: Relatório do período. São Paulo: CETESB, 1991. 191p.

20 - PUPO, N. I. H. Manual de pastagens e forrageiras. Campinas: Instituto Campineiro de Ensino Agrícola, 2000. 343p.

21 - PRUDNET. Capim-elefante Paraíso Matsuda (On line, 09/ 04/2000, http://www.prudnet.prudnet.com.br/)

22 - RIBEIRO, M. D.; KWAI, H.; TÍNEL, P. R. et al. Experimento piloto da lagoa de aguapé para tratamento de esgoto bruto. Revista DAE, São Paulo, v. 46, n. 144, p.82-6, 1986.

23 - SILVA, P. C. M.; ZETTL, B. J. E.; NETTO, D. B.; RAMOS, A M. Projeto Baronesa. Rio de Janeiro: Instituto de Pesquisas da Marinha, 1978. 15p.

24 - STRANO, H. C. V. C. Obtenção e caracterização de concentrado protéico de aguapé (Eichhornia crassipes). Dissertação, (Mestrado). Piracicaba, SP, 1997. Escola Superior de Agricultura Luiz de Queiróz, Universidade de São Paulo.

25 - URQUHART, G. M. et al. Parasitologia veterinária. Rio de Janeiro: Guanabara Koogan, 1998. 273p.

26 - XAVIER, D. F.; ALVIM, M. J. A.; BOTREL, M. A. Gramíneas forrageiras para formação de pastagens em áreas montanhosas. Revista dos Criadores, São Paulo, n. 822, p.32-5, 1998 .

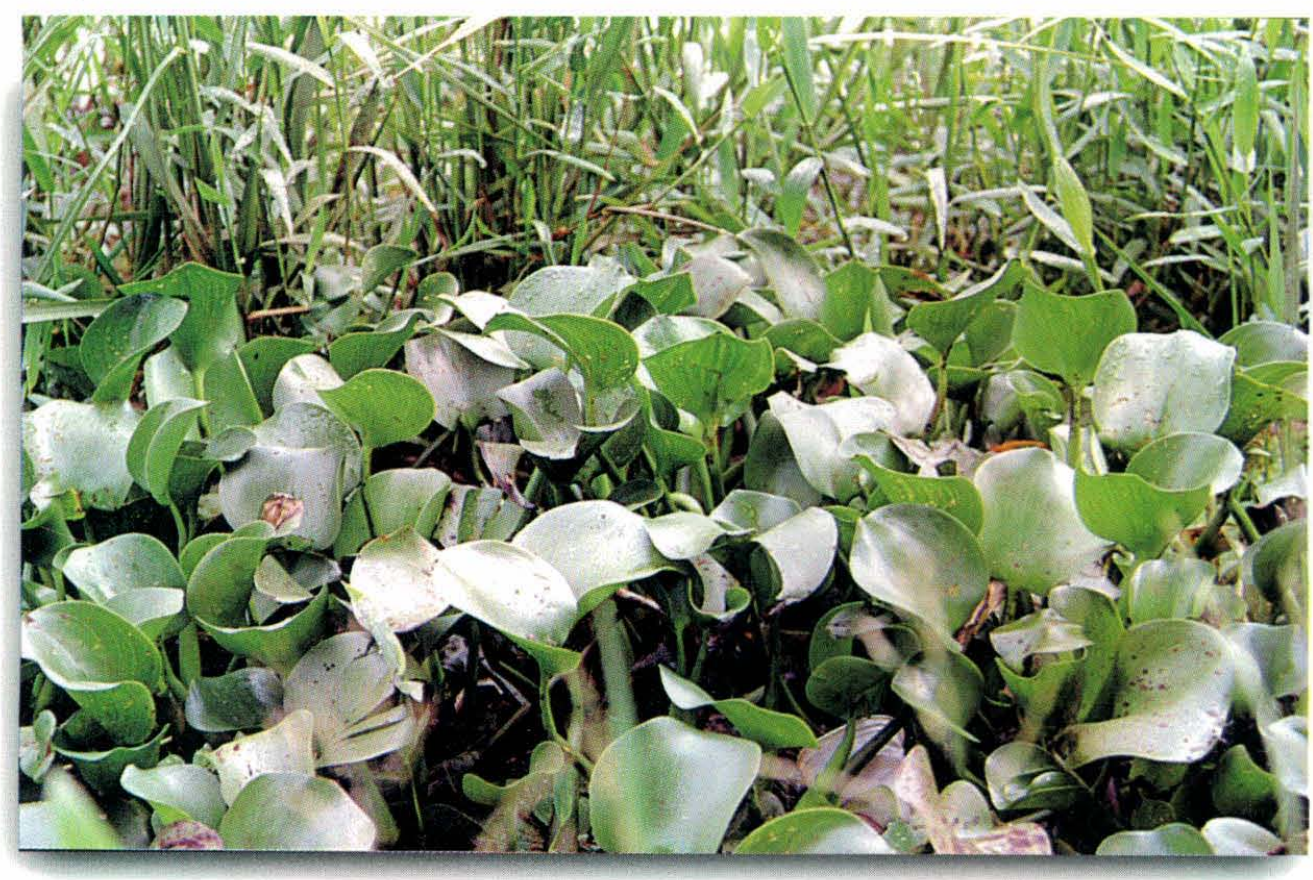

